\title{
Use of Dispersive Liquid-Liquid Microextraction and UV-Vis Spectrophotometry for the Determination of Cadmium in Water Samples
}

\author{
J. Pérez-Outeiral, E. Millán, and R. Garcia-Arrona \\ Department of Applied Chemistry, Faculty of Chemistry, University of the Basque Country (UPV/EHU), \\ P.O. Box 1072, 20800 San Sebastian, Spain \\ Correspondence should be addressed to R. Garcia-Arrona; rosa.garcia@ehu.es
}

Received 16 January 2014; Revised 13 May 2014; Accepted 13 May 2014; Published 26 May 2014

Academic Editor: Lu Yang

Copyright (C) 2014 J. Pérez-Outeiral et al. This is an open access article distributed under the Creative Commons Attribution License, which permits unrestricted use, distribution, and reproduction in any medium, provided the original work is properly cited.

\begin{abstract}
A simple and inexpensive method for cadmium determination in water using dispersive liquid-liquid microextraction and ultraviolet-visible spectrophotometry was developed. In order to obtain the best experimental conditions, experimental design was applied. Calibration was made in the range of $10-100 \mu \mathrm{g} / \mathrm{L}$, obtaining good linearity $\left(R^{2}=0.9947\right)$. The obtained limit of detection based on calibration curve was $8.5 \mu \mathrm{g} / \mathrm{L}$. Intra- and interday repeatability were checked at two levels, obtaining relative standard deviation values from 9.0 to $13.3 \%$. The enrichment factor had a value of 73 . Metal interferences were also checked and tolerable limits were evaluated. Finally, the method was applied to cadmium determination in real spiked water samples. Therefore, the method showed potential applicability for cadmium determination in highly contaminated liquid samples.
\end{abstract}

\section{Introduction}

Cadmium is one of the most toxic heavy metals $[1,2]$. Due to its low damaging concentration levels and to the complexity of the matrix of samples, a prior preconcentration and separation step is frequently necessary in its determination. Liquid-liquid microextraction (LLME) emerged from the classic liquid-liquid extraction (LLE) overcoming one of its major drawbacks by reducing the amount of organic solvents. From the LLME introduction, different approaches have been developed [3]; among them is dispersive liquidliquid microextraction (DLLME) presented by Rezaee et al. in 2006 [4]. In this method, a cloudy solution is formed after the fast injection of a suitable mixture of extraction and disperser solvents into the aqueous phase. Thus, due to the large superficial area in contact between the phases, analytes in the aqueous sample are rapidly extracted into the fine droplets of extraction solvent. After extraction, phase separation is achieved by centrifugation. This technique offers several advantages such as high recoveries, high enhancement factors, and rapidity. Moreover, it may be considered environmentally friendly, due to the use of reduced amount of organic solvents. In addition, it is simple and inexpensive, since neither very specific reagents nor costly laboratory equipment is required $[5,6]$.

For cadmium determination DLLME has been coupled to different spectrometry detection techniques, such as atomic absorption (AAS), atomic fluorescence, inductively coupled plasma with optical emission (ICP-OES), and total reflection $\mathrm{X}$-ray [7-11]. Due to the difficulty in adapting the microvolume of extraction solvent to the necessary volume in conventional UV-Vis spectrophotometers, the coupling to UV-Vis spectrophotometry has only been recently achieved. This problem has been sometimes solved by evaporation and/or dilution of the organic phase or by using special instrumentation $[12,13]$.

The goal of this work was to develop a simple and inexpensive method for determination of cadmium in aqueous samples by coupling DLLME and UV-Vis spectrophotometry with a microcapacity cuvette. In this way, loss of sensitivity linked to the dilution of the organic phase and increase of the price due to the special instrumentation may be avoided. In 
order to select the best experimental conditions, a planned experimental design was run. The chosen procedure was validated and applied to the determination of cadmium in different water samples.

\section{Materials and Methods}

2.1. Reagents and Apparatus. All analytical grade reagents and solvents used were purchased from Panreac Química S.A. (Barcelona, Spain), except for carbon tetrachloride that was obtained from VWR International Eurolab S.L. (Barcelona, Spain). Working solutions of cadmium and dithizone were daily prepared. The $\mathrm{pH}$ of the extraction was adjusted just before the use with a weekly prepared $\mathrm{NaOH} / \mathrm{KCl}$ solution. All solutions were preserved in the fridge while not being used. Doubly distilled water was used throughout the whole work.

A Spectrophotometer 8453 UV-Vis Diode Array System (Agilent Technologies, Spain) with the software "UV-Visible Chemstation Rev. A. 10.01" and an $80 \mu \mathrm{L}$ cuvette (Hellma GmbH \& Co. KG, Germany) were used.

The extractions were made in a vessel with a thermostatic jacket joined to a Lauda Ecoline Re 104 E100 thermobath (Lauda, Germany). Values of cadmium concentration for the enrichment factor evaluation were obtained by measurements in the 7700X ICP-MS (Agilent Technologies, Spain). Experimental design was performed and the results were evaluated using Statistica Software (StatSoft, Tulsa, USA).

2.2. Procedure. Microextraction was accomplished in a tube containing $7.5 \mathrm{~mL}$ of sample at $\mathrm{pH} 12.8 \pm 0.2$ and $1.5 \mathrm{~mL}$ of disperser solvent (methanol). The mixture sample/dispersant was brought to $40^{\circ} \mathrm{C}$. Then, $150 \mu \mathrm{L}$ of a $34 \mathrm{mg} / \mathrm{L}$ solution of dithizone (chelating agent) in chloroform (extraction solvent) was added. The mixture was stirred at $1000 \mathrm{rpm}$ for 3 min to form a cloudy solution, in which chloroform was dispersed as fine droplets to extract the complex cadmium dithizone. This solution was centrifuged at $3500 \mathrm{rpm}$ for $1 \mathrm{~min}$, and the dispersed droplets were deposited at the bottom of the tube. $60 \mu \mathrm{L}$ of the sedimented phase was transferred to the microcuvette for determination in the spectrophotometer. The extraction procedure is schematically shown in Figure 1.

2.3. Water Samples. Two commercial drinking mineral water samples (DW1, DW2), tap water (TW), snow water (SW), river water (RW1), and irrigation channel water (RW2) were analyzed. All samples were filtered through a $0.45 \mu \mathrm{m}$ micropore filter, and different volumes (from 0.5 to $2.5 \mathrm{~mL}$ ) were diluted up to $10 \mathrm{~mL}$ with the $\mathrm{NaOH} / \mathrm{KCl}$ solution.

\section{Results and Discussion}

3.1. Study on the Absorption Spectra. Due to its high efficiency, dithizone was selected as chelating agent for extraction and determination of cadmium by UV-Vis spectrophotometry [14]. Absorbance of the complex $\left(\mathrm{Cd}(\mathrm{HDz})_{2}\right)$ was measured in the wavelength of the maximum absorption
(516 nm for chloroform, $517 \mathrm{~nm}$ for carbon tetrachloride), which corresponded to the wavelength of the minimum absorption for dithizone.

3.2. Selection of Working Conditions. There are several parameters affecting the extraction process. Some of the experimental conditions were fixed according to working characteristics.

In stirring step, agitation speed and time were high enough to form the cloudy solution (1000 rpm, $3 \mathrm{~min})$. In the sedimentation step, centrifugation rate and time were the minimum that allowed collecting the cloudy solution into a sedimented drop (3500 rpm, $1 \mathrm{~min}$ ).

Other variables were univariately studied. $\mathrm{pH}$ was studied in the range of 4.0-13.0, obtaining better results at high levels of $\mathrm{pH}$, where extraction efficiency is higher and the dithizone does not interfere in the analysis [15]. Effect of salt addition was investigated at two levels, without salt and at $10 \%(\mathrm{~W} / \mathrm{V})$ addition. The best results were obtained without salt addition.

The remaining considered experimental variables were studied using experimental design. Taking into account their high density, extraction capacity, and low solubility in water, chloroform and carbon tetrachloride were selected as extraction solvents [6]. Due to their different characteristics (boiling points, water solubility, and interactions with the different dispersants) efficiency of both solvents could not be compared in the same conditions. Hence, two different designs for finding the better experimental conditions for each solvent were done. Regarding the volume of extraction solvent, the minimum volume which gave manageable sedimented phase $(100 \mu \mathrm{L}$ for carbon tetrachloride and $150 \mu \mathrm{L}$ for chloroform) was chosen.

A $2^{4}$ full factorial design with temperature, volume and type of dispersant, and dithizone concentration was made for each extraction solvent [16]. Levels of the factors were chosen based on previous experiments. Concentration of dithizone was selected in the way that in both cases the net amount of chelating agent was the same. A summary of experimental design and its results are included in Table 1.

The levels of the nonsignificant variables were fixed at the values which gave better responses, $0.5 \mathrm{~mL}$ of dispersant and ethanol for carbon tetrachloride and $34 \mathrm{mg} / \mathrm{L}$ concentration of dithizone and methanol for chloroform. Temperature was fixed at the high level in both cases because a further increase of the temperature led to problems in the collection of the sedimented phase. For the same reason, when chloroform was used, the disperser solvent volume was fixed at high level. When carbon tetrachloride was used the concentration of dithizone was fixed at $154 \mathrm{mg} / \mathrm{L}$.

Absorbance in the best conditions of both extraction solvents was compared. Carbon tetrachloride gave a slightly higher value of absorbance but not enough to compensate its higher toxicity and cost compared with those ones of chloroform. Hence, chloroform was selected for further experiments.

Taking into account the experimental design, $1.5 \mathrm{~mL}$ of methanol, $150 \mu \mathrm{L}$ of a $34 \mathrm{mg} / \mathrm{L}$ solution of dithizone in chloroform, and $40^{\circ} \mathrm{C}$ of temperature were the chosen experimental 


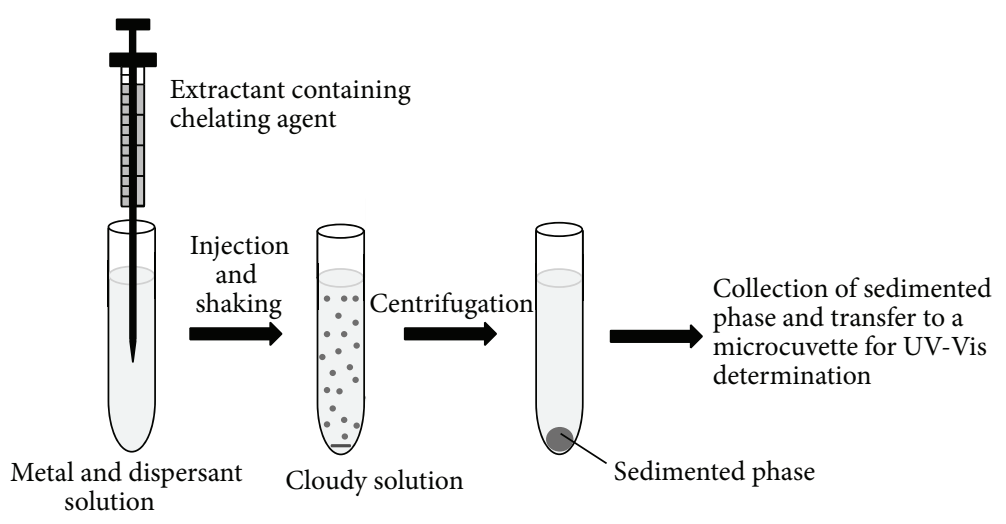

FIGURE 1: Extraction procedure scheme for determination of cadmium.

TABLE 1: Resume of the experimental designs' conditions and results for determination of cadmium with two extraction solvents using DLLME and UV-Vis spectrophotometry.

\begin{tabular}{lcccc}
\hline Factor & Low level & High level & Factor significance & Sign of effect \\
\hline & & Carbon tetrachloride & & \\
Temperature $\left({ }^{\circ} \mathrm{C}\right)$ & 25 & 50 & Significant & Nositive \\
Volume of dispersant $(\mathrm{mL})$ & 0.5 & 1.5 & Significant & Negative \\
Dithizone concentration $(\mathrm{mg} / \mathrm{L})$ & 52 & 154 & Nonsignificant & Positive \\
Type of dispersant & Ethanol & Methanol & Significant & Negative \\
\hline & 25 & Chloroform & Significant & Positive \\
Temperature $\left({ }^{\circ} \mathrm{C}\right)$ & 0.5 & 40 & Nonsignificant & Negative \\
Volume of dispersant $(\mathrm{mL})$ & 34 & 1.5 & Nonsignificant & Positive \\
Dithizone concentration $(\mathrm{mg} / \mathrm{L})$ & Ethanol & Methanol & \\
Type of dispersant & &
\end{tabular}

Screening designs.

$2^{4}$ full factorial designs.

Total number of runs: 32 (with duplicates, in four blocks).

conditions. Those levels, $7.5 \mathrm{~mL}$ of aqueous phase, $\mathrm{pH} 12.8 \pm$ 0.2 , no salt addition, $3 \mathrm{~min}$ of extraction at $1000 \mathrm{rpm}$, and $1 \mathrm{~min}$ of centrifugation at $3500 \mathrm{rpm}$ were the final working conditions.

3.3. Analytical Characteristics. The correlation coefficient $\left(R^{2}=0.9947\right)$ showed a good linearity in the studied range $(10-100 \mu \mathrm{g} / \mathrm{L})$. Limit of detection (LOD) was calculated based on the residual standard deviation of the calibration curve [17]. The obtained value $(8.5 \mu \mathrm{g} / \mathrm{L})$ was little higher than some of those obtained when more sensitive techniques such as FAAS and ICP-OES are coupled to DLLME $[8,10]$. Precision of the method was evaluated at two concentration levels (20 and $80 \mu \mathrm{g} / \mathrm{L}$ ). For intraday repeatability ten measurements were carried out in the same day. For interday repeatability twelve experiments were performed in three days during two weeks. The relative standard deviation percentages (RSD) ranged from 9.0 to $13.0 \%$ for intraday repeatability and from 9.0 to $10.9 \%$ for interday repeatability.For these analyte concentrations, RSDs between 15 and $21 \%$ are acceptable [18]. Hence, the obtained results showed satisfactory precision.

Enrichment factor (EF) was calculated as the relation between the concentration of cadmium in the sedimented phase obtained after the extraction and the initial concentration in the sample. Both concentrations were evaluated by inductively coupled plasma-mass spectroscopy (ICP-MS). EF had a value of 73 , which is among the EFs obtained in the previous mentioned works $[7,8,10]$.

3.4. Interferences. Due to the fact that dithizone can form complexes with other metals, interferences from other present cations in samples may occur frequently. The effect of potentially interfering ions in the developed method was studied in an $80 \mu \mathrm{g} / \mathrm{L}$ cadmium solution. Tolerable limit was taken when the interfering ion/cadmium molar ratio did not cause a relative error in the signal higher than $10 \%$. Molar ratio tolerable limits were the following: 250 for $\mathrm{Al}^{3+}, 100$ for $\mathrm{Ca}^{2+}, 10$ for $\mathrm{Pb}^{2+}, 1$ for $\mathrm{Mg}^{2+}, \mathrm{Mn}^{2+}, \mathrm{Co}^{2+}$, and $\mathrm{Zn}^{2+}$, and 0.1 for $\mathrm{Fe}^{3+}, \mathrm{Ni}^{2+}$, and $\mathrm{Cu}^{2+}$.

3.5. Application to Real Samples. No cadmium was found in the collected water samples. All of them were spiked at $40 \mu \mathrm{g} / \mathrm{L}$, except for DW1 that was spiked at 20 and $80 \mu \mathrm{g} / \mathrm{L}$. Each determination was made in triplicate and the results were evaluated on the basis of recovery $(\mathrm{R}, \%)$ and repeatability (RSD, \%). The results showed recoveries 
ranging from 90 to $109 \%$ and RSDs between 3 and $9 \%$. Thus, the proposed method can be successfully applied to the determination of cadmium in real water samples giving accurate and reproducible results.

\section{Conclusions}

A simple and inexpensive method for determination of cadmium has been developed by coupling DLLME and UVVis. DLLME confers some advantages since it is rapid, simple, and environmentally friendly. On its behalf, UV-Vis spectrophotometry, in spite of its lower sensitiveness compared with other techniques for determination of cadmium, grants the mentioned benefits. Coupling of these two techniques has been successfully achieved by the use of a microlitercapacity cuvette. This form of connection allows avoiding the inconveniences of previous DLLME-UV-Vis coupling ways.

The proposed method showed good precision, repeatability, and reproducibility, and it was successfully applied to real spiked samples. This method is especially suitable when the analytical laboratories have no funds for acquisition of high cost equipment. In conclusion, the proposed method could be applied to the determination of cadmium in highly contaminated water samples.

\section{Conflict of Interests}

The authors declare that there is no conflict of interests regarding the publication of this paper.

\section{Acknowledgment}

Jessica Pérez-Outeiral gratefully acknowledges the financial support in the form of a predoctoral fellowship from the Basque Government (Department of Education, Linguistic Policy and Culture).

\section{References}

[1] G. M. Naja and B. Volesky, "Toxicity and sources of Pb, Cd, Hg, $\mathrm{Cr}$, As and radionuclides in the environment," in Heavy Metals in the Environment, L. K. Wang, J. P. Chen, Y. Hung, and N. K. Shammas, Eds., pp. 16-18, CRC Press, Taylor \& Francis Group, Boca Ratón, Fla, USA, 2009.

[2] J. S. Casas, V. Moreno, A. Sánchez, J. L. Sánchez, and J. Sordo, "Introducción a la toxicología metálica: $\mathrm{Cd}, \mathrm{Hg}$ y $\mathrm{Pb}$," in Química Bioinorgánica, S. A. Síntesis, Ed., pp. 275-285, Madrid, Spain, 2002.

[3] A. Sarafraz-Yazdi and A. Amiri, "Liquid-phase microextraction," TrAC-Trends in Analytical Chemistry, vol. 29, no. 1, pp. $1-14,2010$.

[4] M. Rezaee, Y. Assadi, M. R. Milani Hosseini, E. Aghaee, F. Ahmadi, and S. Berijani, "Determination of organic compounds in water using dispersive liquid-liquid microextraction," Journal of Chromatography A, vol. 1116, no. 1-2, pp. 1-9, 2006.

[5] A. Zgoła-Grześkowiak and T. Grześkowiak, "Dispersive liquidliquid microextraction," TrAC-Trends in Analytical Chemistry, vol. 30, no. 9, pp. 1382-1399, 2011.
[6] X.-H. Zang, Q.-H. Wu, M.-Y. Zhang, G.-H. Xi, and Z. Wang, "Developments of dispersive liquid-liquid microextraction technique," Chinese Journal of Analytical Chemistry, vol. 37, no. 2, pp. 161-168, 2009.

[7] E. Z. Jahromi, A. Bidari, Y. Assadi, M. R. M. Hosseini, and M. R. Jamali, "Dispersive liquid-liquid microextraction combined with graphite furnace atomic absorption spectrometry. Ultra trace determination of cadmium in water samples," Analytica Chimica Acta, vol. 585, no. 2, pp. 305-311, 2007.

[8] F. S. Rojas, C. B. Oịeda, and J. M. C. Pavón, “Dispersive liquidliquid microextraction combined with flame atomic absorption spectrometry for determination of cadmium in environmental, water and food samples," Analytical Methods, vol. 3, no. 7, pp. 1652-1655, 2011.

[9] Q. Zhou, N. Zhao, and J. Xiao, "Preconcentration and sensitive methodology for the determination of cadmium in environmental waters using dispersive liquid-liquid microextraction prior to analysis by atomic fluorescence spectrometry," Atomic Spectroscopy, vol. 32, no. 2, pp. 62-67, 2011.

[10] E. S. dos Silva, L. O. Correia, L. O. dos Santos, E. V. S. dos Vieira, and V. A. Lemos, "Dispersive liquid-liquid microextraction for simultaneous determination of cadmium, cobalt, lead and nickel in water samples by inductively coupled plasma optical emission spectrometry," Microchimica Acta, vol. 178, no. 3-4, pp. 269-275, 2012.

[11] E. Marguí, I. Queralt, and M. Hidalgo, "Determination of cadmium at ultratrace levels in environmental water samples by means of total reflection X-ray spectrometry after dispersive liquid-liquid microextraction," Journal of Analytical Atomic Spectrometry, vol. 28, no. 2, pp. 266-273, 2013.

[12] X. Wen, Q. Yang, Z. Yan, and Q. Deng, "Determination of cadmium and copper in water and food samples by dispersive liquid-liquid microextraction combined with UV-vis spectrophotometry," Microchemical Journal, vol. 97, no. 2, pp. 249-254, 2011.

[13] V. Andruch, L. Kocúrová, I. S. Balogh, and J. Škrlíková, "Recent advances in coupling single-drop and dispersive liquid-liquid microextraction with UV-vis spectrophotometry and related detection techniques," Microchemical Journal, vol. 102, pp. 1-10, 2012.

[14] Z. Marczenko, "Chapter 12 cadmium," in Separation and Spectrophotometric Determination of Elements, pp. 194-202, Ellis Horwood Limited, Halsted Press, 1986.

[15] G. H. Morrison and H. Freiser, "Solvent extraction," in Comprehensive Analytical Chemistry. Volume IA: Classical Analysis, C. L. Wilson and D. W. Wilson, Eds., pp. 147-209, Elsevier Science, Amsterdam, The Netherlands, 1965.

[16] P. W. Araujo and G. Brereton, "Experimental design. I. Screening," TrAC-Trends in Analytical Chemistry, vol. 15, no. 1, pp. 26-31, 1996.

[17] P. Konieczka and J. Namieśnik, "Method validation," in Quality Assurance and Quality Control in the Analytical Chemical Laboratory: A Practical Approach, pp. 146-147, CRC Press, Taylor \& Frances Group, Boca Ratón, Fla, USA, 2009.

[18] M. Rambla-Alegre, J. Esteve-Romero, and S. Carda-Broch, "Is it really necessary to validate an analytical method or not? That is the question," Journal of Chromatography A, vol. 1232, pp. 101109, 2012. 

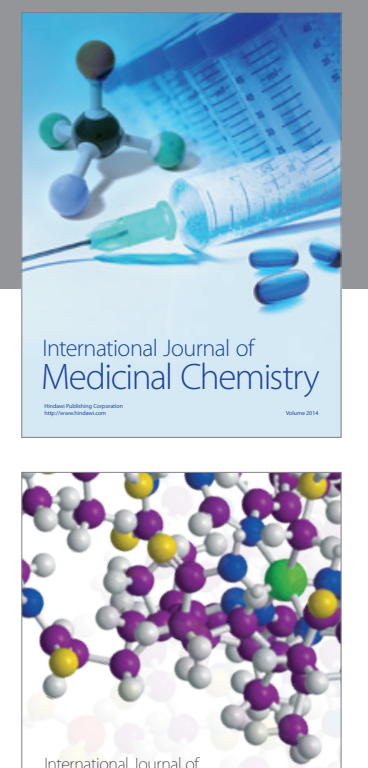

\section{Carbohydrate} Chemistry

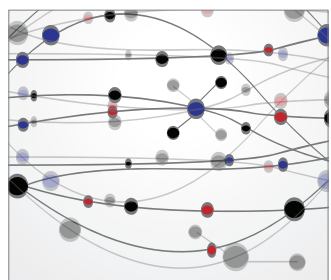

The Scientific World Journal
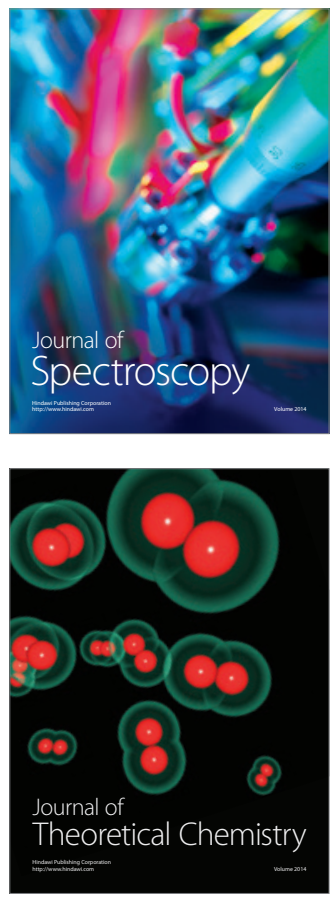
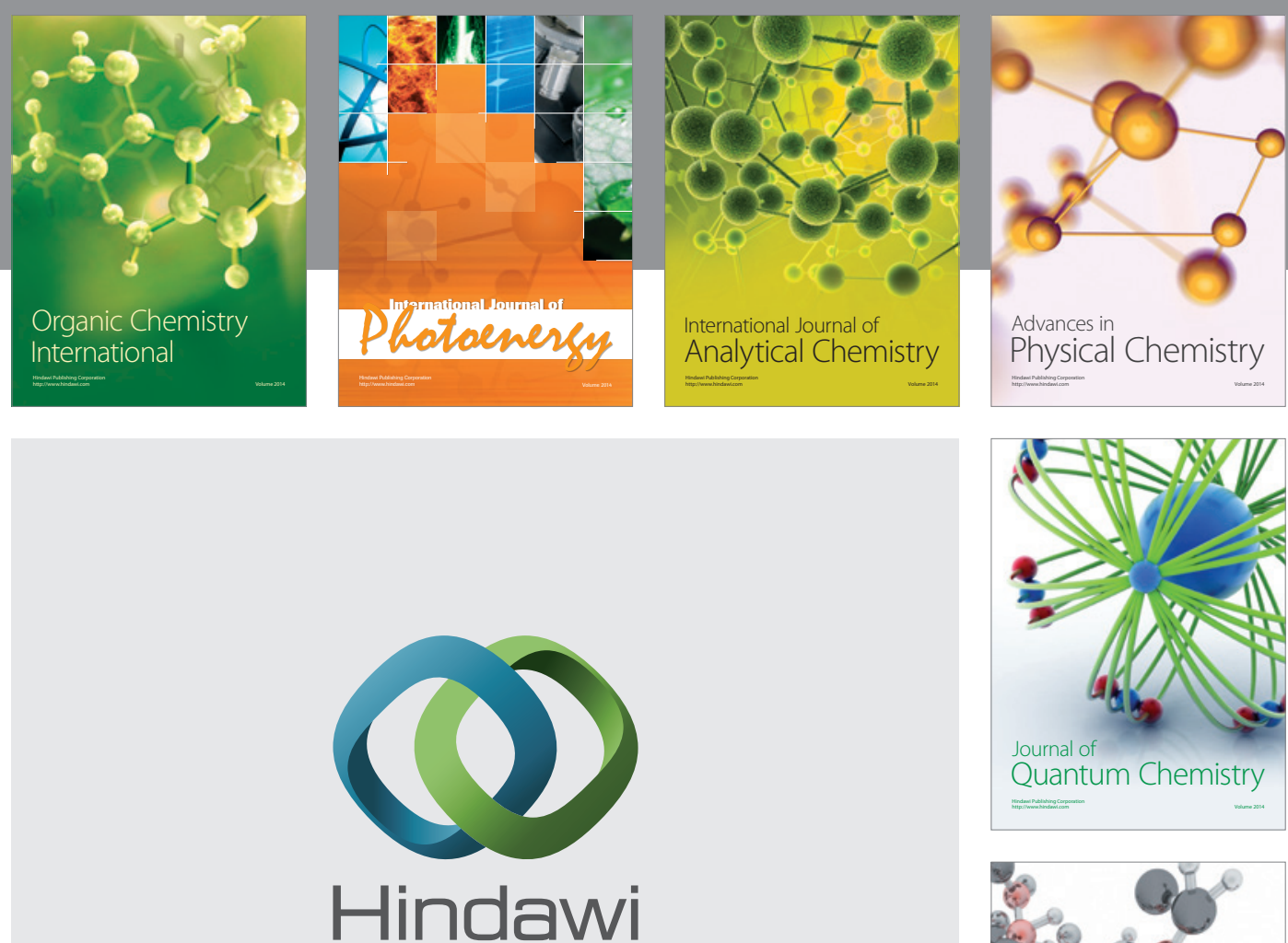

Submit your manuscripts at

http://www.hindawi.com

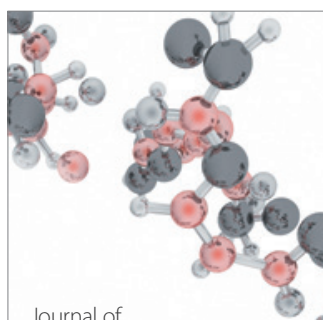

Analytical Methods

in Chemistry

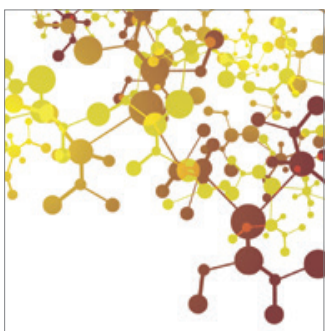

Journal of

Applied Chemistry

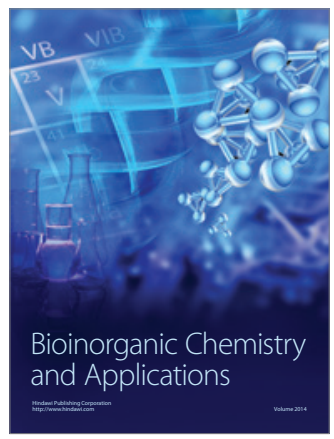

Inorganic Chemistry
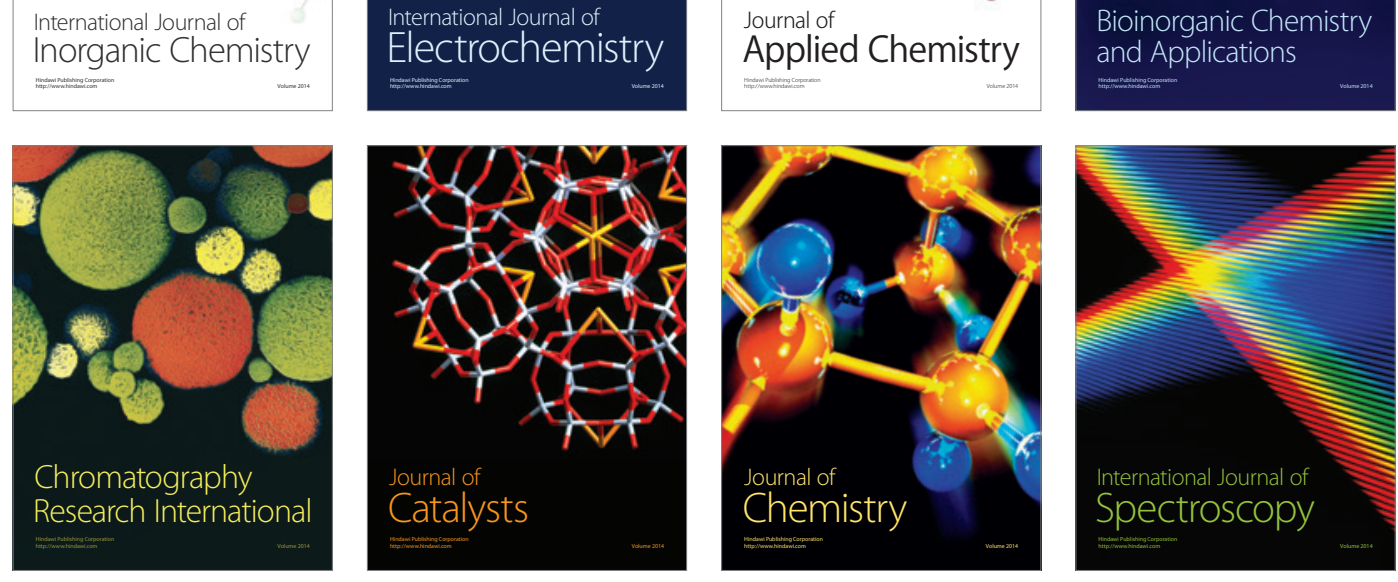